\title{
Research on SaaS-based model of teaching resources platform
}

\author{
He Pan \\ Information technology teaching and Management Center \\ Jilin Agricultural University \\ Changchun,,China \\ panhe@jlau.edu.cn \\ +8613756550845
}

\begin{abstract}
SaaS model as a new software model, can provide convenient, fast, low-cost way to build an auxiliary teaching platform for the user. The SaaS model based teaching resources construction platform, SaaS model summarizes the advantages compared to the traditional mode of teaching resources on the platform construction of the frame structure are discussed.
\end{abstract}

Keywords-SaaS; cloud computing; resource platform; virtualization

With the deepening of education reform, appearance of the Teaching Resource Platform changes students’ learning. So that students exhibit autonomous, personalized features, Increasingly shows vigor booming. but As the number and variety of platforms continue to expand teaching resources, Resource utilization is low, Retrieval difficulties, Resources for sustainable development is not strong, the lack of resources to build awareness of service, information and resources can not be effectively shared. Cloud computing made, so to maximize the functionality of a personal computer, will all the information and resources are packaged as "cloud services"

Contents of this paper is to build a SaaS model is applied to assisted teaching platform, raised the cost of auxiliary teaching platform based on SaaS framework, improve teaching resources and maintenance, auxiliary teaching platform to better serve the teaching service.

Saas Platform Introduction

\section{INTRODUCTION}

\section{A. Concept of Saas}

Saas are the Software Services. This is a new software model, and a mode of delivering software through Internet. Users do not need to purchase software and software required to deploy the appropriate hardware and software resources, Only need to lease the corresponding service can use the functions provided by the software anytime, anywhere. Without the need for software maintenance, Service providers will help users manage and maintain software, SaaS provides a convenient, fast and cost-effective platform for building models of teaching resources

\section{B. SaaS Features}

Internet access software uses B / S model development. Users simply access the Internet, you can access the Web

\author{
Taihao $\mathrm{Li}^{*}$ \\ Information technology teaching and Management Center \\ Jilin Agricultural University \\ Changchun,,China \\ lth@jlau.edu.cn
}

software, without geographical and time constraints on. Popular service SaaS service is popular user-oriented, it was not developed specifically for a user, but rather to provide a large suite of services to meet the needs of most users.Integration is open SaaS platform provides highly integrated applications, integrated data interface components.

SaaS platform provides a safe platform for each application subsystem a unified security services, including user authentication, permissions, authentication, etc.; same time, the platform can be combined with the security services security solutions throughout the system to provide a comprehensive security solution.

\section{SAAS MODEL ADVANTAGES IN BUILDING A PLATFORM OF TEACHING RESOURCES}

\section{A. Learning Resources Cloudreduce hardware} investment costs

Traditional teaching resources platform construction must be invested in computer hardware, including servers, network devices, etc. With hardware constantly updated, constantly expanding platform application requirements, but also need to regularly update the hardware device.This platform is concerned, it will take a lot of costs. In the SaaS model , Minimal hardware investment, Large amounts of data and applications are stored in the "cloud", Users only need to lease (or use) the appropriate resources to complete, No need to consider the performance of the hardware, maintenance, upgrades and other issues.Platform for large-scale leasehold resources, small scale leasehold fewer resources, can reduce hardware investment costs. Assisted teaching platform builders can put more resources into the construction of the platform content.

lower platform software development costs, increase development speed and quality of secondary education platform software development is the focus of the entire platform, aided teaching platform is the key to success. In traditional software development platform, the platform builders need to start from the bottom, every technical details to be resolved. It consumes a lot of time and resources, and software development capabilities for builders also have high demands, some of the non-computer professional teachers may encounter difficulties.

In the SaaS model, you can take advantage of a large number of already very mature service to build the platform, 
technology Difficulty and time will be a very big improvement.

\section{B. Easier to implement resource sharing}

Due to a large number of functions rely on the "service" to achieve shared between different platforms will become very easy: If you use a different platform is the same "service", these platforms can share resources; "service" if you are using different, you only need the "service" will be able to make changes on the sharing of resources.

\section{C. change the existing teaching model}

The large number of "service" in the form of performance-based SaaS model aided teaching platform functionality, in a cloud computing environment, these services can be easily pushed onto different devices. At this time, access to the platform's tools not confined to the "Browser" on a large number of intelligent devices, including PC, mobile phone, PDA, smart TV, etc. can be accessed assisted teaching platform. Students can always use the phone to learn, experiment; teacher can always correcting homework, answering students' questions; locations of various types of simulation experiments can be extended to any occasion with Internet access dormitories, classrooms, home, etc., can be completed without interruption experiment project, it will completely change the current mode of teaching.

\section{SAAS PLATFORM FRAMEWORK DESIGN TEACHING RESOURCES}

Aided teaching platform based on SaaS model is generally constituted by a multi-layer system(figure 1). Including service access layer, a set of service interfaces, business management, platform services layer, business application layer, database layer, system security platform. Service interface is responsible for a variety of terminal equipment interface definitions, access and interface customization, teaching aids unified management platform information. Business management is responsible for the management of business applications, including operating personnel management, user roles, permissions, billing and other unified management. Service platform services layer is responsible for system resources, data management, and platform provided by the entire system .The core of the system. Business application layer platform provides business application modules, including courseware services, video services, simulation services. Link layer is responsible for database access and control data. System Security Platform is responsible for the safety and security of the entire system, including the security infrastructure, business applications, system security, security system, security management, security management is the center of the whole system is the core of the system.

\section{CONCLUSION}

As an emerging SaaS software model, can provide users with a rich, low-cost services. On the secondary vocational colleges teaching platform construction, can provide convenient, fast, low-cost construction mode. In this mode, the auxiliary teaching platform will be the new face appears, drive change throughout the teaching mode.

\section{ACKNOWLEDGMENT}

Subject of the Twelfth Five-year Plan for Science of Education in Jilin Province: 《Research and Implementation of Teaching Resouces Sharing System on Cloud Computing from data center 》 (GH13181)

\section{REFERENCES}

[1]Zhang Hui. Cloud - Based Open Platform Building Research of Teaching Resources [J]. Computer Technology and Development. 2012 (1) : 202-204, 208

[2]Zhou Xi . College Accounting SaaS simulated practice of information technology-based teaching and research [J].Communication of Finance and Accounting. 2011 (7) : 38- 40.

[3]Zhang Weiyang, She minggao. Research on E-government architecture based on SaaS model[J]. Computer \& Digital Engineering. 2011 (4) : :115-118.

[4]Xiao Shenping. Practice and experience to create a modern vocational education platform[J]. Chinese Vocational and Technical Education

[5]Yang Yu-jiang, Huang Jian, Zhang Bing. Construction Project Quality Management Information ServicePlatform Based on SAAS [J].Construction Quality. 2011(9) : 1 - 4. 


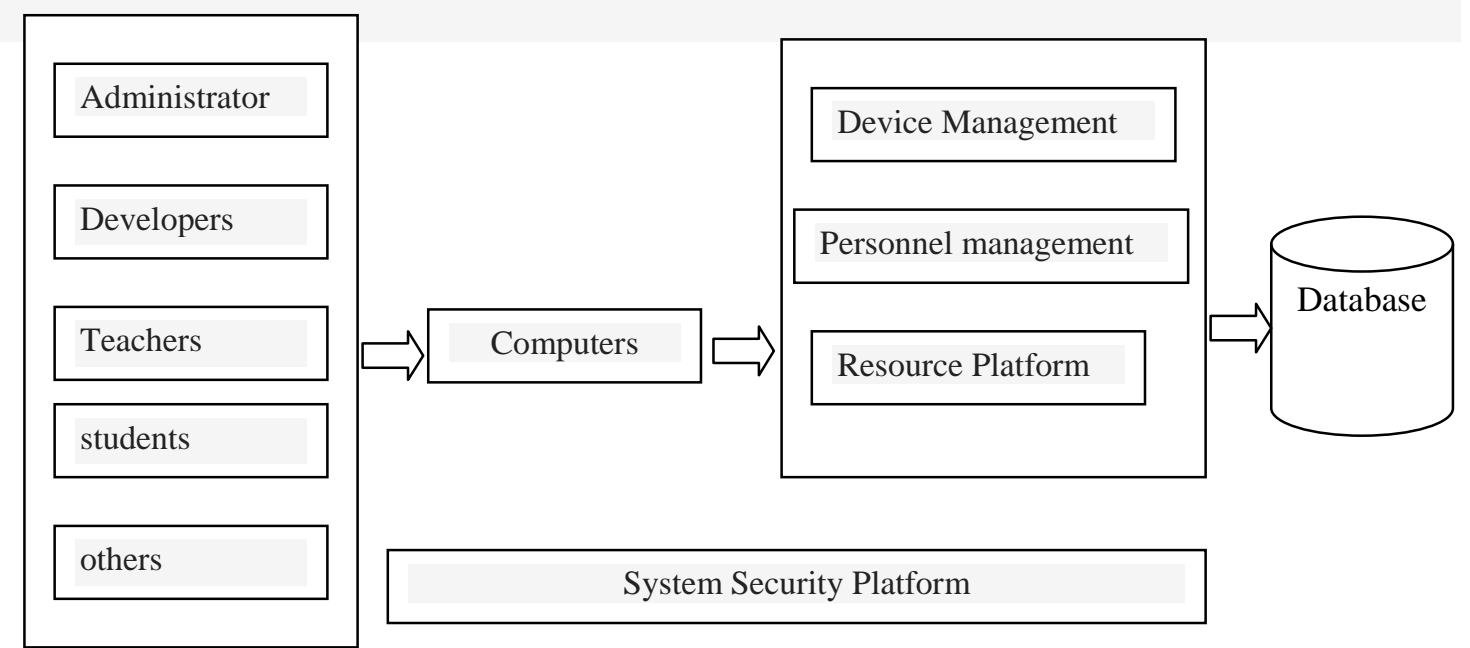

Figure 1 SaaS platform framework design teaching resources 